\title{
Up to Date Mathematical Model for Analysing of Cylindrical Worm Power with Bevel-Gear
}

\author{
Balajti, Zsuzsa ${ }^{1, a}$, Nandorine Toth, Maria ${ }^{1, b}$ \\ ${ }^{1}$ Department of Descriptive Geometry, University of Miskolc, Hungary \\ abalajtizs@abrg.uni-miskolc.hu, ${ }^{b}$ ntm@abrg.uni-miskolc.hu
}

Keywords: worm gear, driving, mathematical model

\begin{abstract}
The developed general mathematical-kinematical model for examination of mating of cylindrical and conical helicoids and their tools - furthermore the helicoids surfaces are on identical axis -, which is suitable to deal with examination at the same time. This paper shows the newest mathematical-kinematical model to analyzing the mating of cylindrical worm gear with bevel gear.
\end{abstract}

\section{Introduction}

Now day's technology, it is the computer-aided or fully automated systems that take over the designing processes of products, technology and tools of production [7, 8]. The computer support of engineering work is the most important condition for increasing the efficiency of production and enhancing the quality of the products.

A great number of areas in the machine industry use helical surfaces - in the form of worm drive pairs [5], driving pins, screw pumps, screw compressors, toothing tools, etc. - and accordingly, a great number of institutions and companies are involved in their design, production, certification and application.

The newest drive pairs with favourable hydrodynamic relations [1], a high load capacity and good efficiency are able to reduce the loss of energy in drives considerably. As regards the loss of energy it does matter, namely - and this holds true for all types of drives - that among the possible tooth geometrical parameters the ones ensuring favorable connection relations should be used [7].

Building on the literature [2,4] and on the results of our own research work in the field [6], we have chosen as the topic of the publication the discussion of the examination of the cylindrical worm gear power with bevel gear [3]. Our geometrically proper design and production of this surface that can be used for many purposes, it is expedient to elaborate a kinematic model that can also serve as a basis for the development of CAD/CAM/CAQ/CIM systems related to the research topic.

\section{The mathematical kinematical model}

The new mathematical-kinematical model are created by us to analysing of drives and manufactures.

The coordinate systems are as follows:

$\mathrm{K}_{0}\left(\mathrm{x}_{0}, \mathrm{y}_{0}, \mathrm{z}_{0}\right) \quad$ stationary coordinate system

$\mathrm{K}_{1 \mathrm{~F}}\left(\mathrm{x}_{1 \mathrm{~F}}, \mathrm{y}_{1 \mathrm{~F}}, \mathrm{z}_{1 \mathrm{~F}}\right)$ coordinate system following a thread path, joined to worm surface

$\mathrm{K}_{2}\left(\mathrm{x}_{2}, \mathrm{y}_{2}, \mathrm{z}_{2}\right) \quad$ stationary coordinate system of gear

$\mathrm{K}_{2 \mathrm{~F}}\left(\mathrm{x}_{2 \mathrm{~F}}, \mathrm{y}_{2 \mathrm{~F}}, \mathrm{z}_{2 \mathrm{~F}}\right)$ rotating coordinate system of gear

$\mathrm{K}_{\mathrm{k}}\left(\mathrm{x}_{\mathrm{k}}, \mathrm{y}_{\mathrm{k}}, \mathrm{z}_{\mathrm{k}}\right) \quad$ secondary coordinate system

$\mathrm{K}_{\mathrm{S}}(\xi, \eta, \zeta) \quad$ coordinate system of generator curve 


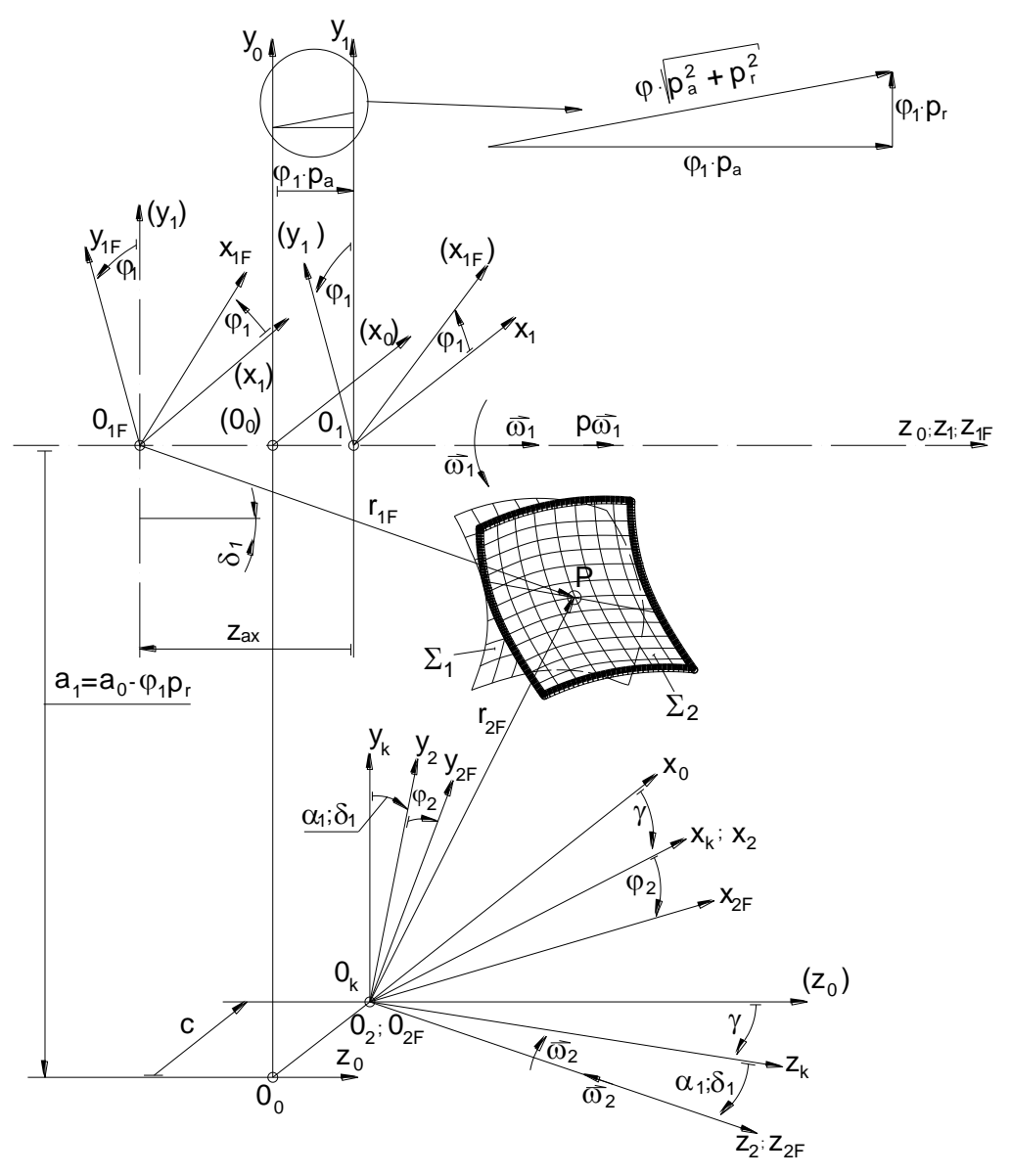

Fig. 1

Modelling of connection between coordinate systems to analaysing of driving pairs

Applied variables and constants:

$\mathrm{a}_{1}$, c $\quad \mathrm{y}, \mathrm{x}$ coordinates of the origin $\mathrm{O}_{2}$ of the gear coordinate system in the $\mathrm{K}_{0}$ coordinate system

$\varphi_{1} \quad$ angular displacement of the helicoids (parameter for movement)

$\varphi_{2} \quad$ angular displacement of the gear

$\mathrm{i}_{21} \quad \mathrm{i}_{21}=\varphi_{2} / \varphi_{1}$ gearing ratio

$\gamma \quad$ lead angle on the reference helicoids

$\alpha \quad$ angle of the tool profile of the helicoids measured in characteristic section

$\mathrm{p} \quad$ parameter of thread

$\mathrm{p}_{\mathrm{a}} \quad$ axial parameter of thread

$\mathrm{p}_{\mathrm{r}} \quad$ tangential parameter of thread

Conditions of movement are interpreted on the right-hand thread surfaces and on the right side of thread profiles. The statements are valid for left-hand thread surfaces.

During our investigations [6] the kinematics of generation was handled so that the helicoids surface followed a thread path and the tool surface performed a rotary motion on the left side of the thread profiles; the lead of thread and generator curve together with signs should be taken into consideration. 
It is necessary to determine generally valid rules for generation of the cylindrical thread surface when discussing geometric problems of manufacturing in general.

\section{Applicability of the Model}

The model applicable for examination of mating of cylindrical and conical helicoids surfaces occurring in the practice -, having constant pitch, by cylindrical shaped cutting tools(e.g. grinding wheel) $[2,4,6]$.

By the help of the model the contact lines can be determined in two ways.

In the direct task the object can be originated from $\mathbf{r}_{\mathrm{F} 1}$ (work piece) surface, and in the indirect (inverse) task the surface of $\mathbf{r}_{\mathrm{F} 2}$ (the cutting tool) is given.

The determined contact line, as a ruling curve, can be used for determination of tools surface, and the work piece surface.

The surface of the work piece can have a cylindrical or a conical base surface having an arbitrary generating surface (with thread cross sectional area).

It is advantageous to give surface of revolution for the cutting tool surface, but other type of surface can be imagined as well, e.g. a single point cutting tool with $\varphi_{2}=$ const [6].

\section{The Transformation Matrices of the Model}

The direct transformation matrices between rotating coordinate systems are:

$$
\mathbf{M}_{2 \mathrm{~F}, \mathrm{~F}}=\mathbf{M}_{2 \mathrm{~F}, 2} \cdot \mathbf{M}_{2, \mathrm{~K}} \cdot \mathbf{M}_{\mathrm{K}, 0} \cdot \mathbf{M}_{0,1} \cdot \mathbf{M}_{1, \mathrm{~F}}
$$

and

$$
\mathbf{M}_{1 \mathrm{~F}, 2 \mathrm{~F}}=\mathbf{M}_{1 \mathrm{~F}, 1} \cdot \mathbf{M}_{1,0} \cdot \mathbf{M}_{0, \mathrm{~K}} \cdot \mathbf{M}_{\mathrm{K}, 2} \cdot \mathbf{M}_{2,2 \mathrm{~F}}
$$

Most frequently applied work piece - and types of cutting tool surface are arranged in the table [6], showing the kinematic parameters which can have the 0 value as well in special cases.

The solution of the direct task (surface of work piece is known), when knew surface $\mathbf{r}_{\mathrm{F} 1}$, the surface $\mathbf{r}_{\mathrm{F} 2}$ and points of contact line are sought using equations: the general method for achieve contact points of elements are valid for any arbitrary point of this contact curve.

It can be written as:

$$
\mathbf{n}^{(1)} \cdot \mathbf{v}^{(12)}=\mathbf{n}^{(2)} \cdot \mathbf{v}^{(12)}=0
$$

The normal vector $\mathbf{n}_{1 \mathrm{~F}}$ can be determined by the next form

$$
\mathbf{n}_{1 \mathrm{~F}}=\frac{\partial \mathbf{r}_{1 \mathrm{~F}}}{\partial \eta} \times \frac{\partial \mathbf{r}_{1 \mathrm{~F}}}{\partial \vartheta}
$$

The relative velocity of the two surfaces can be determined in coordinate system $\mathrm{K}_{1 \mathrm{~F}}$ using the next forms

$$
\mathbf{v}_{1 \mathrm{~F}}{ }^{(12)}=\mathbf{M}_{1 \mathrm{~F}, 2 \mathrm{~F}} \cdot \mathbf{v}_{2 \mathrm{~F}}{ }^{(12)}=\mathbf{M}_{1 \mathrm{~F}, 2 \mathrm{~F}} \cdot \frac{\mathrm{d}}{\mathrm{dt}}\left(\mathbf{M}_{2 \mathrm{~F}, 1 \mathrm{~F}}\right) \cdot \mathbf{r}_{1 \mathrm{~F}}=\mathbf{P}_{1 \mathrm{a}} \cdot \mathbf{r}_{1 \mathrm{~F}}
$$

The transfer matrix can be determined by the next equation 


$$
\mathbf{P}_{1 \mathrm{a}}=\mathbf{M}_{1 \mathrm{~F}, 2 \mathrm{~F}} \cdot \frac{\mathrm{d}}{\mathrm{dt}}\left(\mathbf{M}_{2 \mathrm{~F}, 1 \mathrm{~F}}\right) \cdot \mathbf{r}_{1 \mathrm{~F}}
$$

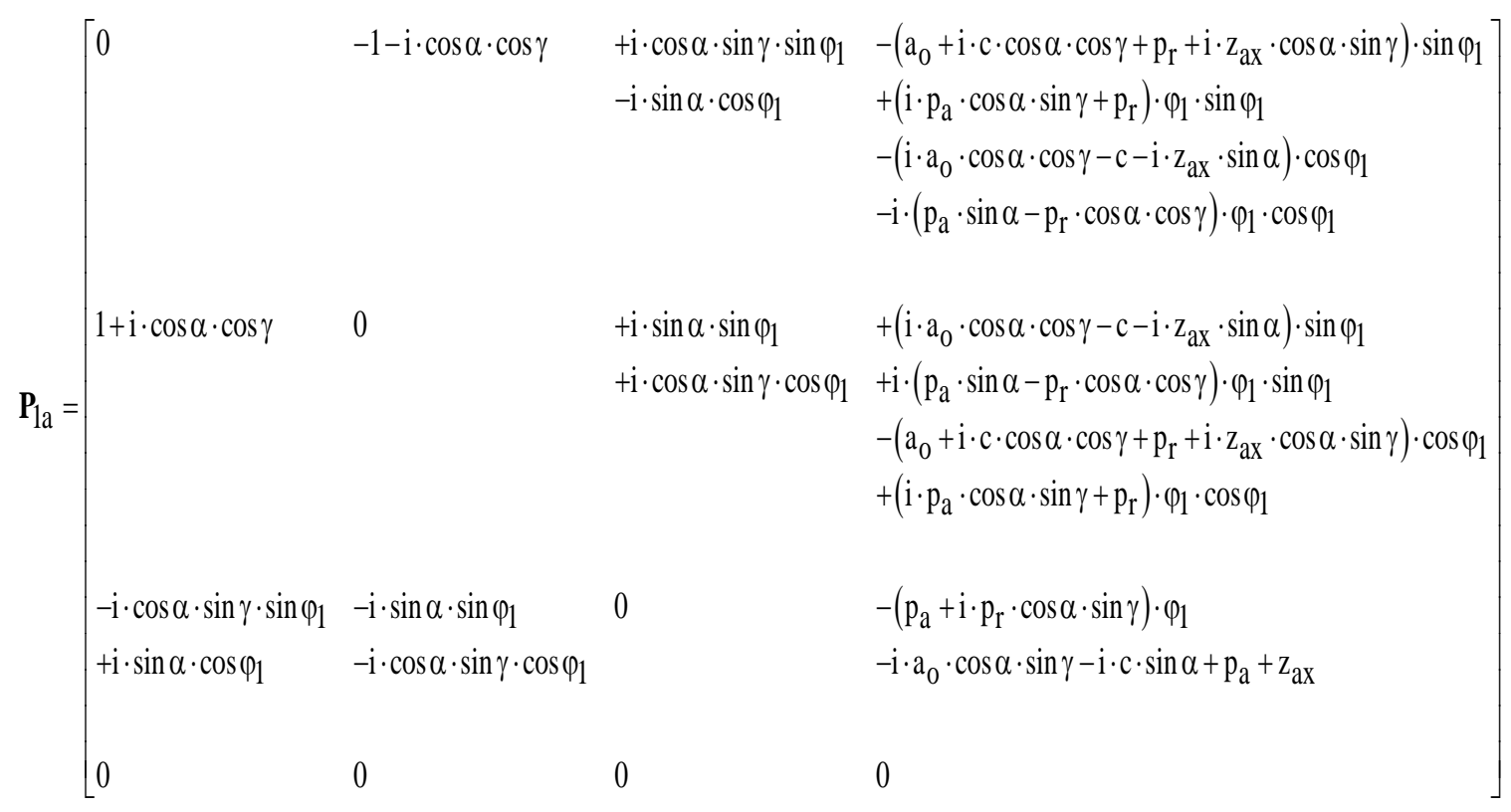
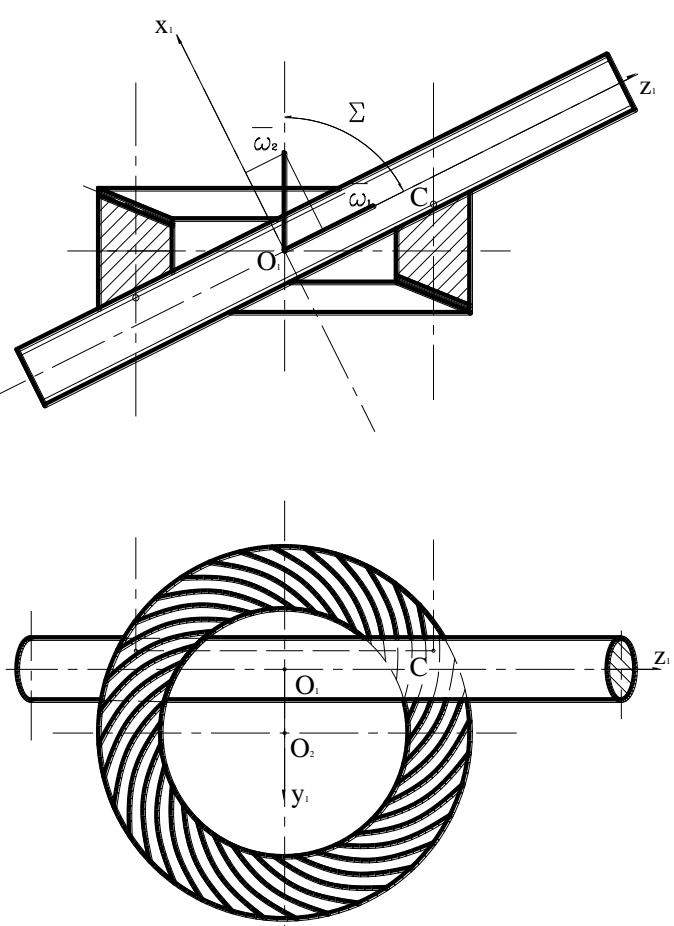

Fig. 2

Connecting of cylindrical worm and cone gear, if the $\alpha=\Sigma$ and $\mathrm{c}$ is distance of $\mathrm{O}_{1}$ and $\mathrm{O}_{2}$ Solving the equation (3) for one of its internal parameters (e.g. $\eta$ ):

$$
\mathbf{n}_{1 \mathrm{~F}}(\eta, \vartheta) \cdot \mathbf{v}_{1 \mathrm{~F}}^{(12)}(\eta, \vartheta)=0
$$

The points of the

$$
\mathbf{r}_{1 \mathrm{~F}}=\mathbf{r}_{1 \mathrm{~F}}(\eta, \vartheta)
$$


The equation of contact curve between surfaces is obtained in the form:

$$
\mathbf{r}_{1 \mathrm{~F}}=\mathbf{r}_{1 \mathrm{~F}}(\eta(\vartheta), \vartheta)=\mathbf{r}_{1 \mathrm{~F}}(\vartheta)
$$

which is suitable for transformation with the next form

$$
\mathbf{r}_{2 \mathrm{~F}}=\mathrm{M} 2 \mathrm{~F}, 1 \mathrm{~F} \cdot \mathbf{r}_{1 \mathrm{~F}}(\vartheta)
$$

The relative velocity of the two surfaces can be determined in coordinate system $\mathrm{K}_{2 \mathrm{~F}}$ using the transformation between coordinate systems $\mathrm{K}_{1 \mathrm{~F}}$ of worm and $\mathrm{K}_{2 \mathrm{~F}}$ of gear:

$$
\mathbf{v}_{2 \mathrm{~F}}^{(12)}=\frac{\mathrm{d}}{\mathrm{dt}} \cdot \mathbf{r}_{2 \mathrm{~F}}=\frac{\mathrm{d}}{\mathrm{dt}}\left(\mathbf{M}_{2 \mathrm{~F}, 1 \mathrm{~F}}\right) \cdot \mathbf{r}_{1 \mathrm{~F}}
$$

The vector $\mathbf{v}_{2 \mathrm{~F}}{ }^{(12)}$ should be transformed into coordinate system $\mathrm{K}_{1 \mathrm{~F}}\left(\mathrm{x}_{1 \mathrm{~F}}, \mathrm{y}_{1 \mathrm{~F}}, \mathrm{z}_{1 \mathrm{~F}}\right)$ to determine the necessary tool surface by the next equation

The contact points generate the contact curves and the bearing pattern, what can be determined by the (3) equation.

\section{Summary}

The model suitable for examination of mating of conical and cylindrical helicoids surfaces with simple or conical gear in practice. The method with our mathematical-kinematical model is suitable for examination of bearing pattern.

\section{References}

[1] I. DUDÁS, GY. VARGA, K. BÁNYAI: Bearing Pattern Localization of Worm Gearing VDIGesellschaft Entwicklung Konstruktion Vertrieb, International Conference on Gears, Tagung Dresden, 22-24. 04. 1996., pp.: 427-441

[2] Goldfarb, L.: Skew Axis Gearing Scheme Synthesis, MPT'91 ISME International Conference on Motion and Powertransmissions, pp.. 649-653

[3] Levai, Imre, Nandorine Toth, Maria: Cylindrical Worm Gear Drive with Cone Gear, Gép, LX, 2009/1, pp.. 37-38

[4] LITVIN, F. L.: Gear Geometry and Applied Theory, Englewood Cliffs, Prentice Hall, NJ., 1994.

[5] Monostori, Renata, Dudas, Illes: Measuring Technical Analysis of Crown wheel, microCAD 2010, Proceedings of International Scientific Conference, March 18-20. 2010., University of Miskolc, Hungary, pp.:135-140

[6] Ovarine Balajti, Zsuzsanna: Development of the Production Geometry of Kinematic Drive Pairs, PhD Dissertation (in Hungarian), University of Miskolc, 2007

[7] Rucki, M., Barisic, B., Varga, G.: Air gauges as a part of the dimensional inspection systems, 2010, Measurement: Journal of the International Measurement Confederation 43 (1), pp. 83-91

[8] Sztankovics, I., Kundrák, J.: Theoretical value of total height of profile in rotational turning, Applied Mechanics and Materials, 2013, 309, pp. 154-161 